\title{
Mindfulness of Career Counselors within the Omani's Context
}

Muna A. Al-Bahrani* \& Bakkar S. Bakkar

Sultan Qaboos University, Sultanate of Oman

\begin{abstract}
This study aimed to explore the variation of Omani career counselors' mindfulness level, in relation to their gender, qualifications, experience, age, and social status. The Mindful Attention Awareness Scale was used to assess the mindfulness level of 164 career counselors from the Sultanate of Oman. The findings showed that mindfulness level was high among career counselors. The results also revealed significant differences due to gender. Males' level of mindfulness was higher than females. No differences were found due to qualifications, experience, age, and social status on the level of mindfulness. Recommendations suggested further research to examine the relationship between mindfulness in career counselors and positive client outcomes.
\end{abstract}

Keywords: Mindfulness level, career counselor, Omani context.

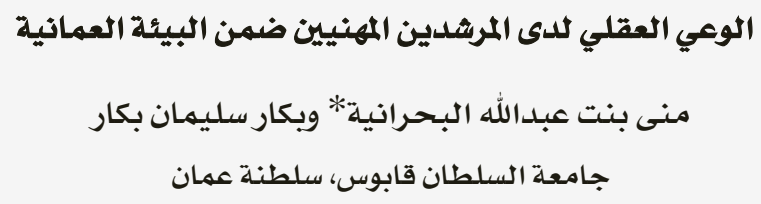

*munabh@squ.edu.om 
Mindfulness is a newly developed concept within the field of psychology. It has sparked growing interest, and its application as a counseling intervention is powerful and widely pertinent; whether being used to enhance traditional counseling approaches or as a prevention strategy (Brown, Marquis, \& Guiffrida, 2013). Recent research demonstrates that mindfulness can gradually achieve outcomes like acceptance, letting go, trust, nonjudgmental attitude, and self-awareness (Birnbaum \& Birnbaum, 2008). This awareness permits the individual to "be present" to reality as it is, rather than to react to it or habitually process it through conceptual filters. Consciousness takes on a clarity and freshness that permits more flexible, more objectively informed psychological and behavior responses (Brown, Ryan, \& Creswell, 2007; Kurash, \& Schaul, 2006).

The mindfulness practice has been described as a vital element of Buddhist, Christian, Hin$\mathrm{du}$, Islamic, Jewish, and Taoist teaching. Mindful awareness practices have appeared in a variety of forms such as yoga and centering prayer. For example, centering prayer teaches individuals the need to wake up to the experiences of the present moment. Individuals learn how to quiet the inner talking and experience silence as well as to return to their intentions of focusing on God (Blanton, 2011). In addition to this, the practice of prayer in Islam teaches individuals to rest their minds from worldly distractions and to focus solely on the act of obedience and submission to Allah's will (Sayeed \& Prakash, 2013). It was documented that a significantly higher alpha wave activity was recorded during the prostration position of the Muslim prayer (Doufesh, Faisal, Lim \& Ibrahim, 2012).

Changes in perception and ways of knowing reality are being expressed through increasing integration of traditions from east and west within the helping paradigm. Within these paradigmatic shifts, mindfulness has emerged as an essential practice to expand consciousness for the purpose of self-observation and knowing the world (Birnbaum \& Birnbaum, 2008). The self or the person of the counselor as Reupert, (2006) noted is more essential that the orientation chosen or the intervention employed within the helping paradigm. Several relationship elements were demonstrably effective including alliance in individual psy- chotherapy, cohesion in group therapy, empathy, and collecting client feedback (Norcross, \& Wampold, 2011).Core skills such as empathy are integrated with empirically supported interventions (Cormier, Nurius \& Osborn, 2013). Empirical studies demonstrated that mindfulness is a predictor of counseling selfefficacy in master's-level and doctoral-level counseling students. Although empathy did not predict counseling self-efficacy, mindfulness did significantly predict empathy (Greason \& Cashwell, 2009).

The processes of mindfulness include concepts such as acceptance and contact with the present moment (Shapiro, Brown, \& Biegel, 2007). Mindfulness and experiential acceptancebased approaches appear to be a viable means for cultivating levels of empathy. As individuals are more mindfully attentive to the their thoughts and feelings, they are more likely to find common ground and greater understanding in their relationships, to engage in higher levels of valued action, and increase their overall quality of life in the process - one moment at a time (Block-Lerner, Adair, Plumb, Rhatigan, \& Orsillo, 2007). Mindfulness may be an important tool not only for cultivating attention capacities in counseling students, but also for helping students learn how to be with clients. The counselor would be able to stay present, fully hear the client's story, and engage empathically (Greason, \& Cashwell, 2009). It tolerates not knowing and clients' distress so that therapists' likelihood of acting out is reduced (Clgolla, \& Brown, 2011; Stauffer \& Pehrsson, 2012).

Mindfulness has the potential to influence positive emotional change in counselors, social workers, and people in general (Birnbaum. \& Birnbaum, 2008). Therapists work requires dealing with clients and their own emotions on a regular basis and they are at risk of occupationally related psychological problems. Therefore, preparation for the role of therapist occurs on both professional and personal levels (Shapiro et al., 2007; Stauffer, 2007). Considering the nature of work, the practice of mindfulness is being used more often both to help clients and to facilitate counselor effectiveness (Brown et al., 2013, Reid, Farragher, \& Ok, 2013; Rothaupt \& Morgan, 2007). Mindfulness attitudes may moderate the depersonalization associated with burnout by helping counselors focus on the client's uniqueness in 
the present moment and alleviate emotional exhaustion through accepting their current emotions and then letting them go (Kurash, \& Schaul, 2006 ; Thompson, Amatea \& Thompson, 2008).

The application of a mindfulness-based stress reduction program reported significant decline in stress, negative affect, rumination, state and trait anxiety, and significant increases in positive affect and self-compassion (Shapiro et al., 2007). Mindfulness and awareness may assist counselors to be more open to their emotional exploration as opposed to avoiding or surpassing emotion which may be detrimental to the quality of therapy (May \& O'Donovan, 2007; Stauffer, 2007). Therefore, the researchers called for integrating mindfulness into therapists' training curriculum in order to enhance their ability to be with their clients and strengthen the therapeutic relationship as well foster self-care (Clgolla, \& Brown, 2011).

Researchers support the importance of examining contextual variations in mindfulness such gender and age. The variations was found among females who showed higher levels of mindfulness. As indicated by Gilbert and Waltz (2010) females were significantly higer in the observatinal factor. This suggests that females are more influenced by contextual differences in the degree to which they are aware of the present moment in a nonjudgmental manner than males (Lilja et al., 2011; Luk, Holman, Kohlenberg, 2008). Females are more able to take the perspective of another person in comparison with men (Davis \& Franzoi, 1991). In addition, in addressing the difficult topic of professionalism within the context of a systems based medical curriculum, females scored higher than males on selfreport awareness and emotional intelligence (Doherty, Cronin \& Offiah, 2013). Conversely, males scored higher than females on a mindfulness' measure (Abdulla \& Alshamsi, 2013). In terms of age, Lilja et al. (2011) noted that older participants obtained higher values on a measure of mindfulness than their younger counterparts. The researcher indicated that it would be interesting to see whether the result related to age, gender, and meditation experience can be replicated in other cultures. However, age, gender, and education were found to be unrelated to mindfulness (Hansen, Lundh, Homman \& Wångby-Lundh, 2009; Josefsson, Larsman, Broberg, \& Lundh, 2011;
McCracken, Gauntlett-Gilbert \& Vowles, 2007).

\section{Statement of the problem}

The effectiveness of mindfulness practice was highlighted within several helping paradigms (Birnbaum, 2008; Napoli \& Bonifas, 2011; Tadlock-Marlo, 2011). For example, using mindfulness in supervision experiences appeared to improve empathy with the client's emotional experience and enhance awareness of functioning as a counselor (Andersson, King \& Lalande, 2010). Further, mindfulness does have the potential to enhance an occupational counselor's ability to practice in a maximally effective from a wide variety of areas of practice. Active listening, non-judgmentally, and perspective taking are fundamental aspects of the client-centered practice philosophy that is embedded within the profession of helping paradigm (Reid \& Farragher, 2013). The reported results showed that counselor trainees who do not avoid their own issues and who are highly attuned to their own emotions and vulnerabilities would be more attuned to the vulnerabilities of others (Trusty \& Watts, 2005). Further, as a result of practicing mindfulness, counselors may be able to reflect the here-and-now of the experience and help clients to gain awareness of the uncomfortable issues that cause problem for them (Stauffer, 2008).

It appears that ongoing practice of mindfulness may be a critical tool for counselors to sharpen their ability to be attentive. The growing interest to practice and explore mindfulness will provide benefits to the recipients of services and foster healthier approaches to life among professionals (Campbell \& Christopher, 2012; O'Driscoll, 2009; Rothaupt \& Morgan, 2007). With a shortage of studies in this area, research is needed to explore the mindfulness construct among counselors because mindfulness has demonstrated great promise and warrants further investigation (Brown et al., 2013). Career counseling profession has only recently developed in Oman. As a response to the national need in increasing career awareness and boosting educational and employment opportunities, in 2008 the Ministry of Education assigned teachers who had Bachelor Degree in Education to be career counselors. To fully fill their career counseling duties, counselors have been exposed to a substantial in-service training workshops. Fur- 
ther, they were prepared academically through a higher diploma program in career guidance and counseling within college of Education at Sultan Qaboos University. This program exposed those counselors to the theoretical and practical part of various topics such as techniques, theories including cognitive and developmental models of individual and group counseling, communication skills, vocational measurements and the design of career programs.

\section{Research Questions}

The main aim of this study was to understand the variation of career counselors' mindfulness level. Two primary questions were investigated:

\section{What is the level of the participants'} mindfulness?

2. Are there any statistical significant differences in the participants' mindfulness in relation to their gender, qualification, experience, age, and social status?

\section{Method}

\section{Participants}

The participants of this study were 164 high schools career counselors who are assigned to provide career counseling services including helping students in the process of selecting their careers. The sample varied in terms of qualification, experience, age, and social status. Table 1 illustrates the characteristics of the sample.

\section{Procedure}

The study was conducted based on the standard procedures that are applied within the Omani context. Questionnaires were distribut- ed among career counselors who work in high schools in Muscat Governorate during the first semester of the academic year 2013/2014. The participation was voluntarily and the participants who volunteered were given the questionnaires package to complete. The participants completed the questionnaire at their own pace and then returned it to the researcher within one month of distribution.

\section{Measure}

The Mindful Attention Awareness Scale (MAAS) was constructed by Brown and Ryan (2003). The scale consists of 15 items, all of which indicate lack of a mindfulness. I One example is "I tend not to notice feelings of physical tension or discomfort until they really grab my attention." The MAAS was positively correlated with measures such as wellbeing, including feelings of autonomy, competence, and positive relations with others. In addition, it was negatively correlated with anxiety, hostility, depression, selfconsciousness, and impulsivity (Brown \& Ryan, 2003).

The items are rated on a 6-point Likert scale (almost always $=1$, very frequently $=2$, somewhat frequently $=3$, somewhat infrequently $=4$, very infrequently $=5$, almost never $=6$ ) .Total scores can range from 15 to 90 and higher scores indicate more mindfulness.

In the present study, the researcher used the MAAS with a 5 -point Likert scale (never $=1$, rarely $=2$, sometimes $=3$, often $=4$, always $=5$ ). The rationales of using the five point scale was to keep the options meaningful to the respondents, so it is clearer and more easily understood. The total score ranged from 15 to 75

Table 1

Demographic Characteristics of the Sample $(\mathrm{N}=164)$

\begin{tabular}{|c|c|c|c|c|}
\hline & & \multicolumn{2}{|c|}{ Gender } & \multirow[t]{2}{*}{ Total } \\
\hline & & Male & Female & \\
\hline Qualification & Higher Diploma & 12 & 27 & 39 \\
\hline \multirow[t]{2}{*}{ Experience } & Short (1-5years.) & 30 & 31 & 61 \\
\hline & Long (6+years) & 57 & 46 & 103 \\
\hline Age & $31-40$ years. & 69 & 53 & 122 \\
\hline \multirow{3}{*}{ Social status } & 41years and above & 8 & 5 & 13 \\
\hline & Single & 9 & 11 & 20 \\
\hline & Married & 78 & 66 & 144 \\
\hline Total & & 87 & 77 & 164 \\
\hline
\end{tabular}


and the mean score is 45 , which was considered as a cut- off point. A score of 15 indicates the highest level of mindfulness awareness, and a score of 75 denotes indicate lowest level of mindfulness. The scale's items were translated by the researcher into Arabic and were back-translated by another researcher in the psychology department.

\section{Reliability}

Cronbach's alphas ranging from .80 to .90 have been reported for MAAS (Brown \& Ryan, 2003). In this study, reliability of the MAAS was estimated in two ways: test-retest reliability and internal consistency. To estimate test retest reliability, a pilot study was conducted twice with an interval of 3 weeks on 20 career counselors who were pursuing their higher diploma in career counseling program at Sultan Qaboos University. The correlation coefficient between the first time scores and the second time scores was $(0.82, \mathrm{p} .<0.01)$. Internal consistency was calculated by Cronbach Alpha for MAAS's items. Cronbach Alpha coefficient for the whole scale was 0.88 . These values indicate appreciable and accepted reliabilities for the MAAS scale.

\section{Results}

In responding to the questions, means and standard deviations were calculated. Both $\mathrm{t}$ test and ANOVA were utilized to examine the effect of the independent variables (gender, qualification, experience, social status, and age) on mindfulness measure.

To answer the first research question concerning the level of the participants' mindfulness, means and standard deviations were obtained as shown in Table 2.

Findings in table 2 reveal that mindfulness level is high, that is, the total scores of mindfulness for male and female counselors are $29.265,32.403$ respectively, and the total score for all is 30.738. These scores are below the cut-off point 45; which means that the level of mindfulness is high among career counselors.

To answer the second research question regarding the differences in the participants' mindfulness in relation to their gender, qualification, experience, age, and social status, ttest and a Univeriate analysis were utilized. Table 3 represents the findings findings of $\mathrm{t}-$ test of experience, social status, and gender. Additionally, Table 4 illustrates the findings of Univeriate of age and qualification.

Table 2

Means and Standard Deviations of Participants' Scores on the MAAS

\begin{tabular}{|c|c|c|c|c|c|c|c|}
\hline & \multirow[t]{2}{*}{ Gender } & \multicolumn{2}{|c|}{ Male } & \multicolumn{2}{|c|}{ Female } & \multicolumn{2}{|c|}{ Total } \\
\hline & & Mean & SD & Mean & SD & Mean & SD \\
\hline Qualification & Higher Diploma & 30.333 & 2.381 & 34.169 & 1.553 & 32.667 & 6.884 \\
\hline \multirow[t]{2}{*}{ Age } & $20-30$ & 32.952 & 2.323 & 36.631 & 1.863 & 34.552 & 7.509 \\
\hline & $31-40$ & 31.185 & 1.326 & 31.228 & 1.216 & 29.770 & 7.044 \\
\hline
\end{tabular}

Table 3

Findings of T-Test of Gender, Experience and Marital Status

\begin{tabular}{clcccccc}
\hline & & $\mathrm{N}$ & Mean & SD & $\mathrm{t}$ & $\mathrm{df}$ & Sig. \\
\hline \multirow{2}{*}{ Experience } & Short & 61 & 31.180 & 1.601 & 0.606 & 162 \\
& Long & 103 & 30.476 & 1.692 & & 0.546 \\
Social status & Single & 20 & 29.800 & 2.291 & -0.622 & 162 \\
& Married & 144 & 30.868 & 1.184 & & 0.535 \\
& Male & 87 & 29.264 & 7.047 & -2.852 & \multirow{2}{*}{162} \\
& Female & 77 & 32.403 & 7.021 & & 0.005 \\
\hline
\end{tabular}

Table 4

Univeriate Analysis on the Effect of Independent Variables on the MAAS

\begin{tabular}{lccccc}
\hline \multicolumn{1}{c}{ Source } & SS & df & MS & F & P \\
\hline Corrected Model & & 32 & 77.498 & 1.709 & 0.019 \\
Intercept & 2479.938 & 1 & 35954.005 & 792.953 & 0.0001 \\
Qualification & 35954.005 & 2 & 70.383 & 1.552 & 0.216 \\
Age & 140.767 & 2 & 63.289 & 1.396 & 0.251 \\
Error & 126.578 & 131 & 45.342 & \\
Corrected Total & 5939.787 & 163 & & \\
\hline
\end{tabular}


Findings in Table 3 shows that there were no significant differences in mindfulness level due to the experience and the social status. Ttest values are respectively: $t(1,162)=0.606$, $(\mathrm{p}=0.546), \mathrm{t}(1,162)=-0.622,(\mathrm{p}=0.535)$. However, there were significant differences in mindfulness due to gender, $t(1,162)=-2.852$, $(p<0.05)$. These differences favored males whose mean was 29.265 , compared with female counselors whose mean was 32.403 which indicaes males' mindfulness awareness level is higher than the females' level.

Table 4 shows that there were no significant statistical differences in mindfulness among career counselors due to qualification and age. $\mathrm{F}$ values were respectively: $\mathrm{F}(1,131)=0.908,(\mathrm{p}$ $=0.342), \mathrm{F}(1,131)=0.105,(\mathrm{p}=0.747), \mathrm{F}(2,131)$ $=1.552,(\mathrm{p}=0.216), \mathrm{F}(1,131)=0.639,(\mathrm{p}=0.425)$ and $\mathrm{F}(2,131)=1.396,(\mathrm{p}=0.251)$.

\section{Discussion}

This study examined the level of mindfulness of career counselors within Omani culture and the level of mindfulness among career counselors was high. To some extent the result was expected because of the uniqueness of the sample. They were all career counselors who had been exposed to some knowledge and training in mindfulness within the cognitive theories such as acceptance and commitment therapy in their higher diploma program. Some components of mindfulness such as active listening, non-judgmentally, and perspective taking are fundamental aspects that are embedded within the profession of helping services such as occupational therapy (Reid \& Farragher, 2013). Additionally, awareness of the present moment is a technique that is embedded in Muslims' lives. Islamic relaxation is a method that incorporates the Islamic tenets of prayer, recitation of the holy Qur'an and Zikr, or recollection of Allah, to obtain a relaxed response of calmness and mindfulness (Syed, 2003).

Another significant finding of this study was related to gender. The difference in scores of mindfulness was found in favor of males compared to females. This finding consistent with the findings reported in studies by (Abdulla \& Alshamsi, (2013); Thompson et al., (2008)). This echoes findings that disagree with what was reported by de Vibe et al., ( 2013) who found that the effect for female students was significant on the mindfulness facet 'non-judging', and that females were more influenced by contextual differences in the degree to which they were aware of the present moment in a nonjudgmental manner than males (Luk et al., 2008). Indeed, AlBahrani, Aldhafri, Alkharusi, Kazem, and Alzubiadi (2013) suggested that the tendency of female to engage in more nonproductive coping involves blaming one self, keeping to themselves, escaping, and anxiety because they are more subject to stressors than males. As Brown et al. (2007) has stated that cognitive, emotional, somatic, and behavioral factors can foster or inhibit mindful states, given what is known about the effects of stress, fatigue, lifestyle choices, and other factors on the quality of conscious states of mind. No statistically significant differences were found due to experience, social status, qualifications, and age on the level of mindfulness. Indeed, this finding is consistent with results reported by (Hansen et al., (2009); McCracken et al., (2007).

There are two primary limitations in this study. Firstly, this study relied exclusively on self-report measures. Secondly, the findings should be interpreted carefully because the measures of mindfulness are fairly new, and most, if not all, suffer from a scarcity of construct and predictive validation. Mindfulness can be assessed through declarative knowledge, meaning that individuals can directly report on those experiential qualities that constitute mindfulness to facilitate the validation of self-report measures of mindfulness (Brown et al., 2007). Despite the limitations of this study, there is sufficient evidence to support the idea that mindfulness is beneficial for clients and for counselors . Research suggests that personal practice of mindfulness by counselors will better position them in their work with clients (Takahashi et al., 2005) and provides them with better assessment of their own strengths and limitations (Cormier et al., 2013).

\section{Recommendation and future research}

Based on the results of this study, several implications can be addressed. First, students as Stauffer (2007) stressed, should be provided with an opportunity to consider the use of self not only to raise self-awareness, but also to consider the ways in which the self might be usefully and professionally enacted during 
training, with their peers and instructors, and when working with clients across various contexts (Reupert, 2009). Second, further research to investigate if a direct relationship exists between

mindfulness in counselors and positive client outcomes would be of enormous relevance to the field (O'Donovan, \& May, 2007).

\section{References}

Abdulla, A., M. \& Alshamsi, A., A. (2013). Mindfulness among the students of the university. The Professor Journal, 205(2), 343-366.

Al-Bahrani, M. Aldhafri, S., Alkharusi, H., Kazem, A., \& Alzubiadi, A. (2013). Age and gender differences in coping style across various problems: Omani adolescents' perspective. Journal of Adolescence, 36(2), 303-309. doi:10.1016/j.adolescence.2012.11.007

Andersson, L., King, R., \& Lalande, L. (2010). Dialogical mindfulness in supervision role-play. Counseling and Psychotherapy Research, 10 (4), 287-294.

Baer, R. A. (2003). Mindfulness training as a clinical intervention: A conceptual and empirical review. Clinical psychology: Science and Practice, 10(2), 125-143.

Birnbaum, L. \& Birnbaum, A. (2008). Mindful social work: From theory to practice. Journal of Religion \& Spirituality in Social Work, 27, 87-104. 18. DOI:

10.1080/15426430802113913

Birnbaum, L. (2008). The use of mindfulness training to create an 'accompanying place' for social work students. Social Work Education, 27 (8), 837-852.

Blanton, P. G. (2011). The other mindful practice: Centering prayer \& psychotherapy. Pastoral Psychology, 60(1), 133-147. doi:http://dx.doi.org/10.1007/s11089010-0292-9.

Block-Lerner, J., Adair, C., Plumb, J. C., Rhatigan, D. L., \& Orsillo, S. M. (2007). The case for mindfulness-based approaches in the cultivation of empathy: Does nonjudgmental, present-moment awareness increase capacity for perspectivetaking and empathic concern?. Journal of marital and family therapy, 33(4), 501-516.
Brown, A., Marquis, A., \& Guiffrida, D. (2013). Mindfulness-Based Interventions in Counseling. Journal of Counseling $\&$ Development, 91, 96-104.

Brown, K. W., \& Ryan, R. M. (2003). The benefits of being present: Mindfulness and its role in psychological well-being. Journal of Personality \& Social Psychology, 84(4), 822848.

Brown, K. W., Ryan, R. M., \& Creswell, J. D. (2007). Mindfulness: Theoretical foundations and evidence for its salutary effects. Psychological Inquiry, 18(4), 211-237.

Campbell, J., \& Christopher, J. (2012). Teaching mindfulness to create effective counselors . Journal of Mental Health Counseling, 34(31), 213-226.

Josefsson, T., Larsman, P., Broberg, A. G., \& Lundh, L. G. (2011). Self-reported mindfulness mediates the relation between meditation experience and psychological well-being. Mindfulness, 2(1), 49-58.

Kurash, S., \& Schaul, J. (2006). Integrating mindfulness meditation within a university counseling centre setting. Journal of College Student Psychotherapy, 20 (3), 53-67.

Lilja, J. L., Frodi-Lundgren, A., Hanse, J. J., Josefsson, T., Lundh, L., Sköld, C., \& ... Broberg, A. G. (2011). Five Facets Mindfulness questionnaire-reliability and factor structure: A Swedish version. Cognitive Behavior Therapy, 40 (4), 291-303. doi:10.1080/16506073.2011.580367

Luk., J., Holman, G., Kohlenberg, R. (2008). Contextual variations of mindfulness an interpersonal and task-oriented contexts: The roles of gender and ethnicity. Psi Chi Journal of Undergraduate Research, 184-190.

May, C., \& O'Donovan, A. (2007). The advantages of mindful therapists. Psychotherapy in Australia, 13(4), 49-53.

McCracken, L. M., Gauntlett-Gilbert, J., \& Vowles, K. E. (2007). The role of mindfulness in a contextual cognitive-behavior al analysis of chronic pain-related suffering and disability. Pain, 131(1), 63-69.

Napoli, M., \& Bonifas, R. (2011). From theory toward empathic self-care: Creating a mindful classroom for social work students. Social Work Education, 30 (6), 635649. 
Norcross, J. C., \& Wampold, B. E. (2011). Evidence-based therapy relationships: research conclusions and clinical practices. Psychotherapy, 48(1), 98.

O'Driscoll, A. (2009). The growing influence of mindfulness on the work of the counseling psychologist; A review. Counseling Psychology Review, 24, 16-23.

O'Donovan, A., \& May, S. (2007). The advantages of the mindful therapist. Psychotherapy in Australia, 13(4), 46-53.

Reid, D., Farragher, J. \& Ok, C. (2013). Exploring mindfulness with occupational therapists practicing in mental health contexts. Occupational Therapy in Mental Health, 29, 79-292.

Reupert, A. (2006). The counselor's use of self in therapy; inevitable presence. International Journal for the Advancement of Counseling, 28, 95-105.

Reupert, A. (2009). Students' use of self: teaching implications. Social Work Education, 28(7), 765-777.

Rothaupt, J., \& Morgan, M. (2007). Counselors ' and counselor educators' practice of mindfulness: A qualitative inquiry. Counseling and Values, 52, 40-54.

Sayeed, S., \& Prakash, A. (2013). The Islamic prayer (Salah/Namaaz) and yoga togetherness in mental health. Indian Journal of Psychiatry, S224-S230. doi:10.4103/00195545.105537

Shapiro, S. L., Brown, K. W., \& Biegel, G. M. (2007). Teaching self-care to caregivers: Effects of mindfulness-based stress reduction on the mental health of therapists in training. Training and Education in Professional Psychology, 1(2), 105.

Stauffer, M. D. (2008). Mindfulness in counseling and psychotherapy: A literature review and quantitative investigation of mindfulness competencies. ProQuest.

Stauffer, M., \& Pehrsson, D. (2012). Mindfulness Competencies for Counselors and Psychotherapists. Journal of Mental Health Counseling, 34, 227-239.

Stauffer, M., D. (2007). Mindfulness in Counseling and Psychotherapy: A Literature Review and Quantitative Investigation of
Mindfulness Competencies. (Doctoral dissertation). Oregon State University, Oregon.

Syed, I. B. (2003). Spiritual medicine in the history of Islamic medicine. Journal of the International Society for the History of Islamic Medicine, 2, 45-49.

Tadlock-Marlo, R. (2011). Making minds matter: Infusing mindfulness into school counseling. Journal of Creativity in Mental Health, 6, 220-233.

Takahashi, T., Murata, T., Hamada, T, Omori, M., Kosaka, H., Kikuchi, M., Yoshida, H., \& Wada, Y. (2005). Changes in EEG and autonomic nervous activity during meditation and their association with personality traits. International Journal of Psychophysiology, 55(2) 199-207.

Thompson, I., Amatea, A., \& Thompson, E. (2008). Personal and Contextual Predictors of Mental Health Counselors' Compassion Fatigue and Burnout. Journal of Mental Health Counselling36 (1), 58-77.

Trusty, J. \& Watts, R. E. (2005). Model of effects of adult Attachment on emotional empathy of counseling students. Journal of Counseling $\mathcal{E}$ Development, 83(1), 66-77. 